\title{
Penerapan Model ECIRR Menggunakan Kombinasi Real Laboratory dan Virtual Laboratory untuk Mereduksi Miskonsepsi Mahasiswa
}

\author{
Hamdani $^{1}$ \\ Pendidikan Fisika FKIP UNTAN \\ hamdani0521@yahoo.com
}

Penelitian ini dilakukan utuk mereduksi miskonsepsi mahasiswa calon guru fisika tentang rangkaian listrik melalui penerapan model ECIRR (Elicit-Confront-IdentifyResolve-Reinforce) menggunakan kombinasi real laboratory dan virtual laboratory. Pengumpulan data dilakukan dengan pemberian tes diagnostik berbantuan CRI (Certainty of Response Index) saat pre test dan post test pada satu kelas. Hasil penelitian menunjukkan jumlah mahasiswa yang mengalami miskonsepsi berkurang dan tanggapan yang positif dari mahasiswa dan dosen tentang penerapan model ECIRR menggunakan kombinasi real laboratory dan virtual laboratory .

Kata kunci : miskonsepsi, model ECIRR, real laboratory, virtual laboratory.

The purpose of this study was to reduce misconceptions held by pre-service physics teacher aboutelectric circuit concepts through the application of the ECIRR (ElicitConfront-Identify-Resolve-Reinforce) model using a combination of real and virtual laboratory. The method used in this study was pre-experimental research design to form a one-group pretest-posttest design is done at a university in Pontianak. Research data were collected by using diagnostic test that include Certainty of Response Index (CRI) and questionnaire.The results showed a decrease in the quantity of misconceptions ECIRR after application of the model using a combination of real laboratory and virtual laboratory. Pre-service teacher andlecturerresponded positivelyto heapplication of the modelusing a combination ofreal ECIRR virtual laboratory and laboratory.

Key words: misconception., ECIRR model, real laboratory, virtual laboratory

\section{Pendahuluan}

Program studi pendidikan fisika sebagai salah satu bagian Lembaga Pendidikan Tenaga Kependidikan (LPTK) harus mampu membekali mahasiswanya dengan pengetahuan, keterampilan, dan kemampuan untuk menjadi calon guru fisika. Aspek yang cukup penting dari kompetensi guru fisika adalah pengetahuan tentang berbagai materi fisika termasuk materi kelistrikan (Nyoto, 2008). Pemahaman konseptual yang dimiliki mahasiswa

\footnotetext{
${ }^{1}$ Hamdani adalah dosen Program Studi Pend. Fisika FKIP Untan
} 
dirasakan kurang, hal ini disebabkan karena adanya miskonsepsi yang dialami mahasiswa.

Hasil penelitian menunjukkan mayoritas mahasiswa mengalami miskonsepsi tentang kelistrikan. Berdasarkan hasil observasi di tempat penelitian dan kajian literatur, miskonsepsi tentang kelistrikan yang berhasil diungkap antara lain arus diserap setiap komponen rangkaian, sehingga arus yang dekat kutub posistif lebih besar dari pada arus dekat kutub negatif dari baterai (McDermott dan Shaffer ,1992; Kuckozer dan Kocakulah, 2007; Berg, 1991), komponen yang diubah hanya mempengaruhi arus dalam komponen sesudahnya dan tidak mempengaruhi arus dalam komponen sebelumnya (local reasoning) (Berg, 1991; Engelhardt dan Beichner, 2004); baterai tunggal yang dirangkai menghasilkan nyala lampu lebih terang dibandingkan dengan dua baterai yang dirangkai seri (Duit dan Rhoneck, 1998); Engelhardt dan Beichner (2004), jika ada dua resistor dirangkai seri, resistor dengan hambatan lebih besar memiliki arus yang lebih kecil (Bilal dan Erol, 2009); jika resistor ditambahkan pada rangkaian paralel, maka hambatan total akan meningkat (Cohen, et al; Dupin dan Johsua, dalam Sencar dan Eryilmaz, 2004).

Dalam konstruktivisme, miskonsepsi merupakan hal yang wajar dalam proses pembentukkan pengetahuan oleh seseorang yang sedang belajar. Pengetahuan itu tidak sekali jadi, tetapi merupakan suatu proses terus-menerus yang semakin sempurna. Bahkan dalam perkembangan mengkonstruksi pengetahuan, mahasiswa dapat bermula dari konsep yang sangat kasar dan sederhana serta tidak lengkap, dan pelan-pelan dalam proses pembelajaran menjadi semakin lengkap, tepat dan benar (Suparno, 2002). Dengan demikian miskonsepsi dapat dijadikan sebagai awal perkembangan pengetahuan yang lebih baik. Miskonsepsi yang dimiliki mahasiswa bertahan lama dalam memori mahasiswa dan akan sulit diubah jika hanya menggunakan strategi mengajar konvensional. Miskonsepsi yang terjadi pada mahasiswa sebagai calon guru harus segera diatasi agar tidak "tertular" kelak pada siswa-siswa yang diajarnya.

Wenning (2008) menyarankan menerapkan model ECIRR ( ElicitConfront-Identify-Resolve-Reinforce) untuk mengatasi miskonsepsi. Model ECIRR menghadirkan konflik kognitif yang selalu diterapkan dalam area pedagogik untuk mengatasi miskonsepsi seperti learning cycle(Karplus), conceptual change theory(Posner, et al), bridging analogies(Clement; Perschard dan Bitbol), micro computer-based laboratory experiences (Thornton dan Sokolof), disequilibrium techniques (Minstrell), inquiry approach(Harrison, et al)dalam Wenning (2008). 
Pemanfaatan simulasi komputer sebagai media pembelajaran dapat digunakan pada penerapan model ECIRR, khususnya pada fase confront yang bertujuan menghadirkan konflik kognitif. Simulasi komputer sebagai pembelajaran interaktif dapat menyediakan kesempatan bagi mahasiswa untuk mempelajari materi setiap saat, diulang-ulang sampai memahami konsep, memahami gejala alam melalui kegiatan ilmiah, dan meniru cara kerja imuwan dalam menemukan fakta, konsep, hukum atau prinsip-prinsip fisika yang bersifat invisible (McKagan, et al, 2008).

Penelitian (Suhandi, dkk, 2008) menunjukkan simulasi virtual dapat meningkatkan pemahaman konsep siswa dan meminimalkan miskonsepsi. Hasil penelitian yang lain menunjukkan strategi pembelajaran dengan simulasi komputer dan virtual lab membantu siswa dan mahasiswa untuk memahami materi-materi fisika (Finkelstein, et al, 2005; McKagan, et al, 2008; Zacharia dan Constantinou, 2008). Siswa memberikan respon yang positif penggunaan simulasi komputer dan virtual lab dalam pembelajaran fisika (Perkins, et al, 2006; Fatik dan Madlazim, 2007). Simulasi komputer dapat digunakan untuk menyediakan pembelajaran interaktif yang menghadirkan fenomena fisika, yang mungkin bertentangan dengan konsepsi peserta didik. Pengalaman ini dapat mendorong peserta didik memodifikasi konsepsi mereka yang keliru (Zacharia dan Anderson, dalam Richards, 2010)

Kegiatan virtual lab tidak selamanya memberikan dampak positif, hasil penelitian menunjukkan adanya penurunan penguasaan konsep (Wainwright; Olugbemiro; Morrel dalam Yang dan Heh, 2007). Untuk mengatasi hal ini salah satu alternatif yang dapat dilakukan adalah mengkombinasikan real lab dengan virtual lab. Penelitian yang dilakukan Chini, et al (2012); Saepuzaman (2011); Zacharia dan Constantinou (2008); Olympiou dan Zacharia (2008) menunjukkan kegiatan kombinasi real laboratory dengan virtual laboratory dapat meningkatkan penguasaan konsep dibandingkan dengan kegiatan real laboratory sajaatau virtual laboratory saja.

Berdasarkan permasalahan di atas perlu dikembangkan pembelajaran yang dapat membantu mahasiswa mereduksi miskonsepsi yang dialaminya. Salah satu alternatif yang diterapkan dalam penelitian ini adalah "Penerapan Model ECIRR menggunakan Kombinasi Real Laboratory dan Virtual Laboratoryuntuk Mereduksi Miskonsepsi”.

\section{Metode}

Metode yang digunakan dalam penelitian ini adalah metode preexperimental designdan metode deskriptif. Untuk mendapatkan gambaran perubahan kuantitas miskonsepsi digunakan metodepre-experimental design, 
sedangkan metode deskriptif untuk mendeskripsikan tanggapan dosen dan mahasiswaterhadap penerapan model ECIRR. Desain penelitian yang digunakan dalam penelitian ini adalah "one-grouppretest-postestdesign" dengan cara memberikan pretest kemudian memberikan perlakuan terhadap satu kelompok dan pada akhir perlakuan diberi evaluasi berupa posttest. Padalembar jawabanpretest dan posttest juga dituliskan Certainty of Response Index (CRI) untuk membedakan mahasiswa yang mengalami miskonsepsi, paham konsep dan tidak tahu konsep. Instrumen yang digunakan dalam penelitian ini berupa tes diagnostik, CRI, dan angket.

Penelitian ini melibatkan 34 orang mahasiswa calon guru fisika semeseter 2 yang mengambil mata kuliah Fisika Dasar 2. Pemilihan sampel dilakukan dengan teknik sampling jenuh yang dilakukan dengan cara semua anggota populasi dijadikan sampel (Sugiyono, 2009).

Uji McNemar digunakan untuk mengetahui signifikansi perubahan miskonsepsi sebelum dan sesudah perlakuan. Pengolahan data angket tanggapan dosen dan mahasiswa terhadap penerapan model ECIRR dilakukan melalui perhitungan persentase.

\section{Hasil dan Pembahasan}

Secara deskriptif penurunan kuantitas miskonsepsi dilakukan dengan menghitung selisish rata-rata persentase miskonsepsi mahasiswa pada saat pretest dan posttest.Rata-rata persentase miskonsepsi mahasiswa pada saat pretest dan posttest disajikan dalam Gambar 1.

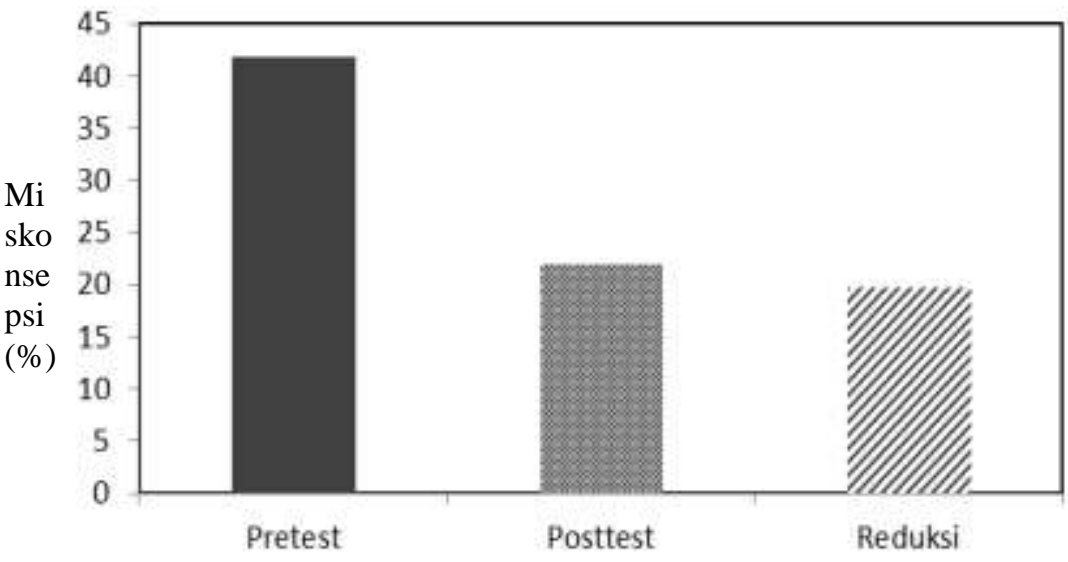


Gambar 1.Rata-rata persentase miskonsepsi mahasiswa sebelum dan setelah penerapan model ECIRR menggunakan kombinasi real laboratory dan virtual laboratory.

Berdasarkan Gambar 1 secara umum setelah pembelajaran terjadi penurunan kuantitas miskonsepsi. Pada saat pretest rata-rata persentase yang mengalami miskonsepsi sebesar $41,81 \%$, sedangkan pada saat posttest ratarata persentase yang mengalami miskonsepsi sebesar 22,04\%. Hasil ini menunjukkan terjadi reduksi miskonsepsi sebesar $19,77 \%$.

Untuk melihat signifikansi reduksi kuantitas miskonsepsi dilakukan uji McNemar. Berdasarkan hasil uji McNemar diperoleh untuk semua butir soal $x^{2}{ }_{\text {hitung }}$ lebih besar dari $x^{2}$ tabel $\left(3,84\right.$ dengan taraf signifikansi 5\%) maka $\mathrm{H}_{\mathrm{a}}$ diterima. Hasil ini menunjukkan penerapan model ECIRR menggunakan kombinasi real laboratory dan virtual laboratory secara signifikan dapat mereduksi miskonsepsi mahasiswa pada setiap butir soal.

Secara deskriptif penurunan miskonsepsi juga terjadi pada semua konsep dalam rangkaian listrik. Rata-rata persentase miskonsepsi mahasiswa pada saat pretest dan posttest pada setiap konsep dalam rangkaian listrik disajikan dalam Gambar 2.

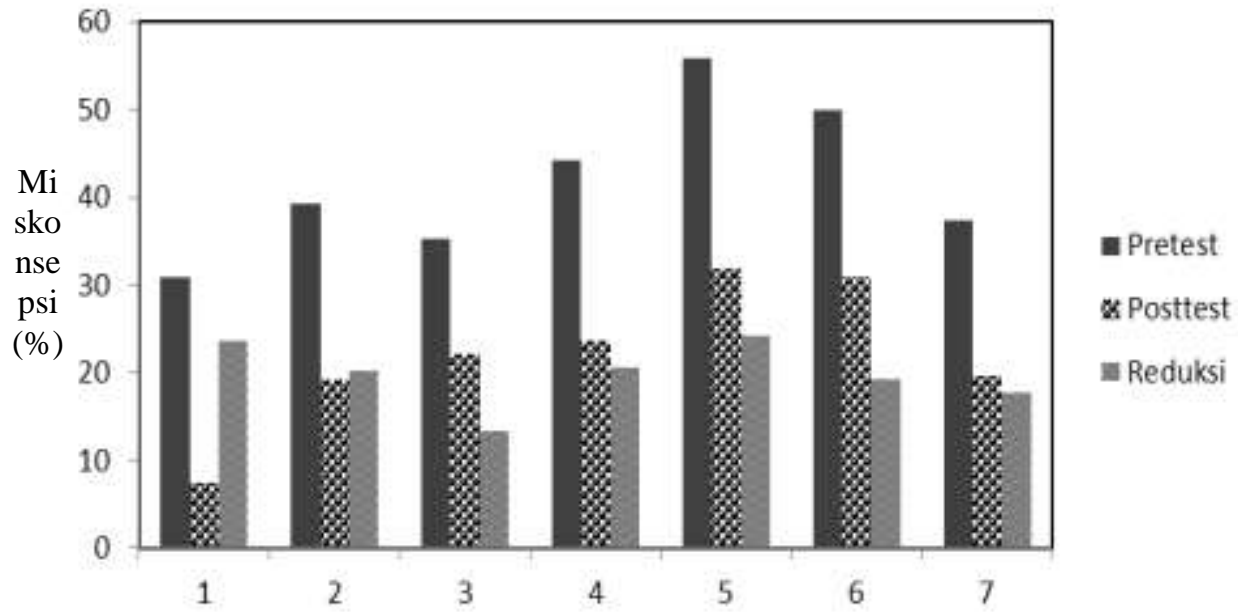

Keterangan : (1) Hukum Ohm, (2) Rangkaian seri, (3) Rangkaian paralel, (4) Perbandingan rangkaian seri dengan rangkaian paralel, (5) Rangkaian majemuk, (6) Hambatan pengganti, (7) Hukum Kirchhoff

Gambar 2.Rata-rata persentase miskonsepsi mahasiswa tiap konsep 
Berdasarkan Gambar 2 dapat diidentifikasi bahwa seluruh konsep yang diujikan pada konsep rangkaian listrik mengalami miskonsepsi.Untuk setiap konsep dalam rangkain listrik rata-rata persentase miskonsepsi pada saat pretest lebih besar dibandingkan dengan posttest.Hal ini menunjukan terjadi penurunan kuantitas miskonsepsi setelah model ECIRR menggunakan kombinasi real laboratory dan virtual laboratory diterapkan. Reduksi miskonsepsi terendah terjadi pada konsep rangkaian paralel sebesar 13,23\%. Hal ini disebabkan karena mahasiswa keliru menerapkan Hukum Ohm dalam rangkaian paralel. Mereka beranggapan jika ada tiga resistor yang berbeda nilai hambatannya dirangkai paralel, maka beda potensial antara ujung-ujung setiap resistor berbeda, semakin besar nilai hambatan maka semakin besar beda potensial antara ujung resistor tersebut. Ada juga mahasiswa yang menganggap bahwa arus pada rangkaian paralel konstan dan beda potensial pada rangkaian seri konstan, hal ini cenderung bersifat hafalan. Selain itu ratarata persentase miskonsepsi tentang rangkaian paralel pada saat pretest tidak besar yaitu 35,29\% yang menempati urutan kedua terendah setelah konsep Hukum Ohm. Reduksi miskonsepsi tertinggi terjadi pada konsep rangkaian majemuk (kombinasi) sebesar 24,12\%. Pertanyaan yang diujikan pada konsep ini mengenai arus listrik dan beda potensial yang mengalir pada salah satu komponen dalam rangkaian kombinasi dan perubahan nyala lampu ketika ada komponen yang putus atau ditambahkan pada rangkaian kombinasi. Tingginya reduksi miskonsepsi pada konsep ini disebabkan kegiatan real lab dan virtual $l a b$ yang sangat membantu mahasiswa dalam mengidentifikasi besar arus lsitrik dan beda potensial pada rangkaian majemuk melalui pengukuran, observasi nyala lampu dan visualisasi gerakan elektron. Pada rangkaian kombinasi pertanyaan yang diajukan cenderung lebih mudah menghadirkan konflik kognitif dalam pikiran mahasiswa. Selain itu rata-rata persentase miskonsepsi tentang rangkaian kombinasi pada saat pretest merupakan yang tertinggi yaitu $55,88 \%$.

Uji Mc Nemar juga dilakukan pada tiap konsep dalam rangkaian listrik untuk menentukan signifikansi perubahan miskonsepsinya. Hasil uji McNemar tiap konsep dalam rangkaian listrik disajikan dalam Tabel 1

Tabel .1Rekapitulasi uji McNemar tiap konsep dalam rangkaian listrik

\begin{tabular}{|l|l|l|l|l|l|l|l|l|}
\hline No & $\begin{array}{c}\text { Konsep dalam } \\
\text { Rangkaian Listrik }\end{array}$ & A & B & C & D & E & $\chi^{\mathbf{2}}$ & Keterangan \\
\hline 1 & Hukum Ohm & 0 & 40 & 4 & 19 & 5 & 17,05 & $\mathrm{H}_{\mathrm{a}}$ diterima \\
\hline 2 & Rangkaian seri & 11 & 79 & 26 & 69 & 19 & 40,61 & $\mathrm{H}_{\mathrm{a}}$ diterima \\
\hline 3 & Rangkaian paralel & 2 & 28 & 12 & 17 & 9 & 10,31 & $\mathrm{H}_{\mathrm{a}}$ diterima \\
\hline 4 & Perbandingan rangkaian & 2 & 28 & 10 & 22 & 6 & 15,04 & $\mathrm{H}_{\mathrm{a}}$ diterima \\
\hline
\end{tabular}




\begin{tabular}{|l|l|l|l|l|l|l|l|l|}
\hline & $\begin{array}{l}\text { seri dengan rangkaian } \\
\text { paralel }\end{array}$ & & & & & & & \\
\hline 5 & Rangkaian majemuk & 11 & 42 & 35 & 57 & 25 & 29,78 & $\mathrm{H}_{\mathrm{a}}$ diterima \\
\hline 6 & Hambatan pengganti & 3 & 17 & 15 & 21 & 12 & 12,04 & $\mathrm{H}_{\mathrm{a}}$ diterima \\
\hline 7 & Hukum Kirchhoff & 4 & 42 & 12 & 29 & 15 & 17,45 & $\mathrm{H}_{\mathrm{a}}$ diterima \\
\hline
\end{tabular}

Keterangan:

$\mathrm{A}=$ Mahasiswa yang paham konsep pada pretest, dan miskonsepsi pada posttest

$\mathrm{B}=$ Mahasiswa yang paham konsep pada pretest dan posttest

$\mathrm{C}=$ Mahasiswa yang miskonsepsi pada pretest dan posttest

$\mathrm{D}=$ Mahasiswa yang miskonsepsi pada pretest, dan paham konsep pada posttest

$\mathrm{E}=$ Mahasiswa yang salah satu atau keduanya dari pretest dan posttest tidak tahu konsep

Hasil uji McNemar pada Tabel 1 menunjukkan $x^{2}$ hitung lebih besar dari $x^{2}$ tabel $(3,84$ dengan taraf signifikansi 5\%) untuk semua konsep dalam rangkaian listrik $\left(\mathrm{H}_{\mathrm{a}}\right.$ diterima). Hasil ini menunjukkan penerapan model ECIRR menggunakan kombinasi real laboratory dan virtual laboratory secara signifikan dapat mereduksi miskonsepsi mahasiswa tiap konsep dalam rangkaian listrik.

Bentuk-bentuk miskonsepsi yang diungkap pada penelitian ini juga ditemukan dalam penelitian-penelitian sebelumnya. Bentuk-bentuk miskonsepsi tersebut antara lain.Arus listrik dalam rangkaian seri berkurang pada tahanan atau lampu (consumption model), pada kasus ini mahasiswa menganggap arus yang mengalir pada rangkain seri akan diserap oleh setiap hambatan dengan kata lain pada rangkaian seri komponen yang dekat dengan kutub positif akan memiliki arus yang paling besar. Temuan ini juga tercatat dalam laporan penelitian yang dilakukan oleh McDermott dan Shaffer (1992), Kuckozer dan Kocakulah (2007), Darjito dan Van den Berg (1991), Duit dan Rhoneck, Purba dan Depari (2008), Mursalin (2012). Komponen yang diubah hanya mempengaruhi arus dalam komponen sesudahnya dan tidak mempengaruhi arus dalam komponen sebelumnya (local reasoning), bentuk miskonsepsi ini juga ditemukan oleh Darjito dan Van den Berg (1991), Duit dan Rhoneck, Purba dan Depari (2008). Semakin banyak hambatan dirangkai secara seri, maka arus lsitriknya semakin besar, bentuk miskonsepsi serupa diungkap oleh Engelhardt dan Beichner (2004).Nyala lampu yang dirangkai paralel lebih redup dibandingkan dengan nyala lampu yang dirangkai seri, bentuk miskonsepsi ini juga ditemukan oleh Wainwright, Engelhardt dan Beichner (2004), Kuckozer dan Kocakulah (2007). 
Hasil angket menunjukkan respon dosen dan mahasiswa terhadap penerapan model ECIRR sangat baik. Model ECIRR dapat digunakan untuk menimalisir miskonsepsi yang terjadi karena dalam penerapannya tahapantahapan model ECIRR dapat mengungkap miskonsepsi yang dimiliki mahasiswa, menghadirkan konflik kognitif dalam pikiran mahasiswa, mengkonstruksi sendiri konsep-konsep yang dipelajari mahasiswa, memperbaiki konsepsi yang keliru dan membuat belajar lebih bermakna, membantu memahami konsep-konsep yang bersifat abstrak, memberikan kesempatan berinteraksi dengan teman dan bekerjasama saling membantu dalam kesulitan.

Tahapan-tahapan dalam model ECIRR cocok digunakan untuk mengatasi miskonsepsi karena setiap tahapan memiliki kerangka dan tujuan yang jelas untuk mereduksi miskonsepsi.Pada fase Elicit memeriksa miskonsepsi yang dialami mahasiswa melalui mendeteksi pengetahuan awal mahasiswa. Untuk mengatasi miskonsepsi hal pertama yang perlu dilakukan adalah membuat peserta didik sadar akan konsep awal mereka apakah benar atau keliru, dari konsep awal ini dapat dideteksi miskonsepsi (Suparno, 2005).

Pada fase Confront menciptakan konflik kognitif dalam pikiran mahasiswa. Dalam proses perubahan konsep yang keliru menjadi benar memerlukan prinsip konflik kognitif dalam pikiran seseorang melalui peristiwa anomali berupa fakta yang tidak sesuai dengan dugaan atau konsepsi awalnya (Suparno, 2005).

Pada fase Identfy mengidentifikasi dan menjelaskan miskonsepsi yang dialami mahasiswa.Langkah ini dilakukan agar peserta didik dapat mengklarifikasi dan merevisi konsepsi awal mereka.

Pada fase Resolve membantu mahasiswa mereduksi miskonsepsi yang dialaminya melalui kegiatan real laboratory.Langkah ini dilakukan karena eksperimen atau kegitan real laboratory merupakan cara yang baik untuk mengontraskan pengertian peserta didik dengan kenyataan (Gilbert, Watts, Osborne, Brouwer, McClelland, dalam Suparno, 2005). Melalui hasil percobaan yang berbeda dengan intuisi mahasiswa, maka mahasiswa tertantang untuk mengubah gagasan atau konsepsi mereka.

Pada fase Reinforce memberikan penguatan pada mahasiswa melalui kegiatan virtual laboratory. Tahapan ini dilakukan untuk memperkuat dan meyakinkan mahasiswa untuk mengubah konsepsi mereka yang keliru.Melalui kegiatan simulasi (virtual laboratory) mahasiswa dapat memanipulasi data, mengumpulkan data, menganalisis data dan mengambil keputusan. Dalam simulasi mahasiswa menemukan data yang berbeda dengan yang mereka pikirkan sebelumnya, maka mahasiswa akan mengalami konflik dalam 
pikirannya (konflik kognitif). Hasil simulasi yang bertentangan dengan konsepsi awal mahasiswa yang diulang berkali-kali akan menghasilkan perubahan konsep dalam dirinya (Suparno, 2005). Salah satu pendekatan pembelajaran yang dapat mengatasi miskonsepsi adalah pembelajaran yang melibatkan peran aktif peserta didik dalam pembelajaran (Tarakegn, 2009), hal ini dapat dilakukan melalaui kegitan virtual lab (Jimoyiannis dan Komis, 2000, Zacharia dan Anderson dalam Richards, 2010).Selain itu kegiatan virtual lab dapat digunakan untuk memperbaiki dan mengkonfrontasi miskonsepsi (Hewson, Tao, dalam Jimoyiannis dan Komis, 2000).

Berdasarkan hasil penelitian yang dilakukan tidak semua konsepsi mahasiswa yang keliru dapat diperbaiki, salah satu faktor penyebabnya adalah pada saat kegiatan real lab dan virtual lab interaksi dosen dengan mahasiswa dirasakan kurang.Interaksi yang kurang dikarenakan banyaknya jumlah kelompok yang harus diakomodasi, akibatnya tidak semua kebutuhan mahasiswa terpenuhi.Hal ini sesuai dengan pernyataan Berg (1991) kunci untuk perbaikan konsepsi yang keliru adalah interaksi dengan peserta didik.Selain itu berdasarkan hasil observasi ada beberapa mahasiswa yang kurang berperan aktif dalam kelompoknya. Miskonsepsi pada soal-soal yang sederhana lebih sedikit dibandingkan dengan soal-soal yang memiliki tingkat kesulitan yang lebih tinggi. Temuan ini sesuai dengan hasil temuan Osborne dan Freyberg, Driver et al, Gilbert dan Watss, Hasweh, Halloun dan Hestenes dalam Berg (1991) yang mengungkap soal-soal yang sederhana dapat dikerjakan, tetapi dengan soal yang relatif lebih sulit, miskonsepsi muncul lagi.

\section{Kesimpulan dan Saran}

Berdasarkan hasil penelitian yang telah dilakukan dapat disimpulkan, penerapan model ECIRR menggunakan kombinasi real laboratory dan virtual laboratory dapat mereduksi miskonsepsi rangkaian listrik yang dialami mahasiswa sebesar 19,77\%. Reduksi miskonsepsi tertinggi terjadi pada konsep rangkaian kombinasi sebesar $24,12 \%$ dan reduksi miskonsepsi terendah terjadi pada konsep rangkaian paralel sebesar 13,23\%.

Beberapa saran yang mungkin dapat digunakan untuk meningkatkan keberhasilan upaya membekali mahasiswa yang siap menjadi guru pemula dan penelitian selanjutnya, antara lain:diperlukan manajemen waktu dan pengelolaan kelas yang lebih baik untuk menghasilkan pembelajaran yang efektif; pada saat melaksanakan kegiatan real laboratory sebaiknya setiap mahasiswa telah memiliki keterampilan dasar dalam bekerja di laboratorium, misalkan merangkai rangkaian listrik,; untuk kegiatan virtual laboratory sebaiknya dilakukan tutorial terlebih dahulu sebelum kegiatan praktikum 
dilakukan agar tidak banyak waktu yang terbuang; pengelola laboratorium perlu meningkatkan layanan dengan membenahi petunjuk dan peralatan laboratorium agar memudahakan mahasiswa saat melakukan praktikum.

\section{Referensi}

Berg, V. D. (1991).Miskonsepsi Fisika dan Remediasi. Salatiga: UKSW

Bilal, E. dan Erol, M. (2009). "Investigating Students' Conceptions of Some Electricity Concepts".Latin American Journal of Physics Education. 3, (2), 193-201

Chini, J.J. et al (2012). "Exploration of Factor that Affect the Comparative Effectiveness of Physical and Virtual Manipulatives in an Undergraduate Laboratory".Physical Review Special Topics-Physics Education Research 8, 010113

Duit, R. dan Rhoneck, C.V (1998).Learning and Understanding Key Concepts of Electricity.[Online].http://www.physics.ohio-state.edu (14 September 2012)

Engelhardt , P.V \& Beichner R.J, (2004). “Students' Understanding of Direct Current Resistive Electrical Circuits".American Journal of Physics.72, (1), 98-115

Fatik, Z dan Madlazim (2012).Pengembangan Perangkat Pembelajaran Fisika dengan Lab Virtual PhET Pada Materi Gelombang Elektromagnetik Di SMAN 1 Kutorejo.[Online].http://ejournal.unesa.ac.id (24 Oktober 2012)

Finkelstein, N. D, et al (2005). "When Learning About the Real World is Better Done Virtually: A Study of Substituting Computer Simulations for laboratory Equipment". Physical Review Special Topics-Physics Education Research 1, 010103

Jimoyiannis, A dan Komis, V. (2001). "Computer Silulations In Physics Teaching and Learning: A Case Study On Students' Understanding of Trajectory Motion". Computers and Education.36, 183-204

Kucukozer.H. dan Kocakulah, S. (2007). “Secondary Scholl Students' Misconception about Simple Electric Circuits".Journal of Turkish Science Education. 1, (4), 101-115

McDermott, L.C dan Shaffer, P.S, (1992). "Research As A Guide For Curriculum Development: An Example From Introductory Electricity. 
Part I: Investigation of Student Understanding”. American Journal of Physic. 60, (11), 994-1003

McKagan, et al (2008). "Developing and Researching PhET Simulation for Teaching Quantum Mechanics". Physics Education Technology Journal.www.colorado.edu/istem/pdfs/QMsims.pdf [19 Oktober 2012]

Mursalin (2012). Model Diklat Penanggulangan Miskonsepsi Guru Fisika Pada Topik Kelistrikan dan Kemagnetan Melalui Simulasi Komputer. Disertasi Doktor (tidak dipublikasikan). Bandung: Program Pascasarjana UPI Bandung

Nyoto, (2011). Pengembangan Model Pembelajaran Inkuiri Menggunakan Analogi Pada Konsep Listrik Magmet Untuk Membekalkan Kemampuan Beranalogi Calon Guru Fisika. Disertasi Doktor (tidak dipublikasikan). Bandung: Program Pascasarjana UPI Bandung

Olympiou, G dan Zacharia, Z.C (2008). Introducing Virtual Manipulatives in Science Experimentation for Teaching and Learning at The University Level. [Online]. www.iiis.org (8 November 2012)

Perkins, K. et al (2006). "PhET: Interactive Simulations for Teaching and Learning Physics". Physics Teacher. 44, (1), 18-23

Purba, J.P. dan Depari, G (2008). Penelusuran Miskonsepsi Mahasiswa Tentang Konsep Dalam Rangkaian Listrik Menggunakan Certainty of Response Index dan Interview. [Online]http://file.upi.edu/ Direktori/ FPTK/JUR._PEND._TEKNIK_ELEKTRO/194710251980021JANULIS _P_PURBA/Makalah_Seminar/miskonsepsi_(Invotec).pdf September 2012

Richards, D. S (2010). A Case Study of Students' Conceptions On Electromagnetic Induction While Viewing A series of Video, Animations, and Interactive Simulations. Disertasi Doktor pada The Graduate School College of Education The Pennsylvania State University: tidak diterbitkan

Saepuzaman, D. (2011). Penerapan Model Pembelajaran Inkuiri Dengan kombinasi Eksperimen Nyata-Virtual Pada Materi Rangkaian Listrik Arus Searah Untuk Meningkatkan Penguasaan Konsep dan Keterampilan Proses Sains Siswa SMA. Tesis pada SPs UPI Bandung: Tidak diterbitkan 
Sencar. S dan Erylmaz. A. (2004). "Factors Mediating the Effect of Gender on Ninth-Grade Turkish Students' Misconceptions Concerning Electric Circuit". Journal of Research in Science Teaching. 41, (6), 603-616

Sugiyono.(2009). Metode Penelitian Pendidikan. Pendekatan Kuantitatif, kualitatif dan $R \& D$. Bandung: Alfabeta

Suhandi, A. dkk.(2008). Efektivitas Penggunaan Media Simulasi Virtual Pada Pendekatan Pembelajaran Konseptual Interaktif Dalam Meningkatkan Pemhaman Konsep dan Meminimalkan Miskonsepsi. Laporan Penelitian Hibah Kompetitif UPI. Bandung: FMIPA UPI

Suparno, P (2005). Miskonsepsi dan Perubahan Konsep Pendidikan Fisika. Jakarta: Grasindo

Tarakegn, G. (2009). "Can Computer Simulations Substitute Real Laboratory Apparatus?" Latin American Journal of Physics Education. 3, (3), 506-517

Wenning, C.J. (2008). "Dealing More Effectively With Alternative Conceptions In Science". Journal of Physics Teacher Education Online. 5, (1), 11-19

Yang, K. Y. dan Heh, J. S. (2007). "The Impact of Internet Visual Physics Laboratory Instruction on the Achievment in Physics, Science Process Skills and Computer Attitudes of 10th-Grade Students". Journal of Science Education and Technology. 16, 451-461

Zacharia, Z.C dan Constantinou, C. P. (2008)."Comparing the Influence of Physical and Virtual Manipulatives in the Context of The Physics by Inquiry Curriculum: The Case of Undergraduate students' Conceptual Understanding of Heat and Temperature".American Journal of Physic. $76,(4 \& 5), 425-430$ 